\title{
Modern venereal disease legislation in Denmark
}

\author{
AXEL PERDRUP \\ Rudolph Bergh's Hospital, Copenhagen, Denmark
}

Venereal disease laws and regulations are good illustrations of people's current concept of V.D. With the rising prevalence of V.D. in mind and hoping to find new sign posts, I have studied the summaries of recent V.D. legislation in The International Digest of Health Legislation (WHO, 1965-1970) where since 1964 thirteen countries throughout the world are referred to. All these countries follow the old and well-known principle that sanctions like compulsory treatment and eventually confinement are important provisions to motivate V.D. patients for examination and treatment. Consequently, in most countries, the procedure against V.D. includes cooperation between doctor and police, a cooperation which is otherwise considered only in the case of dangerous epidemics.

The psychological background for severe legal provisions against V.D. lies far back in human history. This fact was recently elucidated by MartinBouyer (1972) who referred to the concept of the sexual act as a sin, which is a conspicuous element of the religions prevailing in Europe: Christianity and Islam. To sin is added fear of the unknown consequences of V.D. Punishment is the primitive reaction to $\sin$ and fear.

In England and in some countries dominated by English political philosophy, a unique respect for the integrity of the individual has been a bulwark against compulsory provisions in the handling of V.D. In countries dominated by Germanic influence and even more in communist countries anti-V.D. laws and regulations prescribe detailed procedures and sanctions.

In the Scandinavian countries the last few years have seen a radical change in the public view of sex, which has resulted in controversy on the value of sanctions and compulsion in the control of V.D. An important basis for this debate is the susceptibility to the influence of sanctions of those groups of young people who are particularly at risk, those which we used to mention as problem groups or vulnerable groups. At the meetings of this Union many important papers have been presented which contribute to our knowledge of these problem groups, and I should like to mention two recent Scandinavian publications:

(1) A thesis by Ekstrøm (1972) demonstrates the socio-psychiatric background of V.D. patients: broken homes, short schooling, poor occupational training, and various forms of rootlessness.

(2) Gustavsson (1971) finds that problem groups behave abnormally or unpredictably because the individuals lack control over their impulses and this leads to exaggerated sexual behaviour starting at an early age. The same problem groups are characterized by other negative deviations from the population's standard behaviour, particularly with regard to minor offences against the law.

If our present knowledge of the problem groups is correlated with the main reasons for the present V.D. situation as they are emphasized by Guthe (1970), it is difficult to choose any field in which the punishment of sources of infection or of defaulters can improve the situation (Table I).

TABLE I Chief reasons for the present resurgence of V.D.

\begin{tabular}{l}
\hline New contraceptive practices \\
\hline Population movements, tourism, migration, etc. \\
\hline Urbanization and industrialization \\
\hline Armed conflicts. Social and economic climate \\
\hline Behavioural changes. Sexual habits in young people \\
\hline Prostitution and homosexuality \\
\hline Inadequate surveillance, public health and epidemiological activities \\
\hline Increased susceptibility. Re-infection. Impaired cross-immunity \\
syphilis/yaws \\
Inadequate diagnostic and treatment facilities, patient management, \\
and training of personnel \\
Differing infectivity and epidemiological characteristics of syphilis and \\
gonorrhoea and their complications \\
Demographic characteristics
\end{tabular}


The history of Danish V.D. legislation (Table II) illustrates the changing concepts of V.D. that have led to changing patterns in the organization of the V.D. services.

TABLE II History of Danish V.D. legislation and factors affecting the organization of the V.D. services

1773

1790

1802

1867

1877

1874

$1875-1900$

1901

1906

1909

1918-1919

1936

1940

1940-1945

1947
Introduction in part of Denmark of venereal disease treatment at public expense

Obligatory treatment free of charge introduced in all Denmark

Treatment of venereal diseases offered free of charge to all foreign sailors in the port of Copenhagen

Notification of venereal diseases in Copenhagen

Notification of venereal diseases throughout Denmark on the same principles as to-day

Regulations for prostitutes with obligatory periodical examinations by a medical officer

Age of rapid expansion and industrialization

Abolition of brothels

Abolition of regulations for prostitutes

Five venereal disease clinics opened in Copenhagen Copenhagen a clearing centre for wounded prisoners
of war

Introduction of sulphonamides

Introduction of diagnostic culturing of $N$. gonorrhoeae (centralized service)

Occupation by German troops

Penicillin treatment of gonorrhoea becoming more widely used

Until 1947 the title of the Danish law was: Law against public Immorality and Venereal Infections. It contained a mixture of provisions against prostitution and procedures against a group of diseases. In 1947 the legislators wished to present a purely antiepidemic law, but public opinion prevented a complete weeding out of the anti-prostitution provisions. Prostitution itself is now designated 'vagrancy'. The law, which is still in force, but which we are trying now to alter, still deals with persons who are suspect of various sorts of immorality; it mentions confinement in hospital for defaulters and imprisonment for up to 2 years if a person exposes somebody to venereal infection. When infecting another person is a criminal offence, it is easy to foresee that individuals will try to escape trouble by denying or by 'forgetting' certain contacts. The Danish Administration of Justice Act states that nobody is obliged to confess a crime committed by himself. This means that the doctor is entitled to ask his patient only about his source of infection and not about his later contacts, since to admit the latter would be to incriminate himself. These laws greatly hamper the work of contact tracing. During the last few years V.D. legislation has been thoroughly discussed by the Danish Society for DermatoVenereology, and the large majority of our members agree that the duties of the medical profession and those of the police should be entirely separated.

The full force of the law is very seldorh invoked, and some may feel that a mere threat will do no harm. Others may think that we should at once abolish all V.D. legislation. The view of the Danish venereologists, expressed in a bill laid before the Danish Parliament this spring, is that the wisest procedure is to maintain a legal basis in order to secure financial appropriations for specific anti-V.D. purposes:

To provide free treatment to all V.D. patients, including foreigners.

To provide technical assistance, e.g. by contact investigators, to doctors charged with the duty of tracing contacts.

To maintain The State Serum Institute-paid for by the state-as a central laboratory service for the whole country.

The transmission of infections to other individuals would cease to be a criminal offence and defaulters would no longer be punished. On the other hand it must be stated that those who deliberately spread venereal infections, and only such persons, are liable to punishment.

Like V.D. laws in other countries, Danish law has hitherto prescribed many very detailed procedures. Laws die hard and many provisions become outdated. Our bill therefore appears simply as a framework and technical details may be changed in accordance with development in the field. It is the duty of the National Health Service to prescribe adequate technical procedures, and it is the intention of the non-governmental Danish Society for DermatoVenereology to appoint a committee to provide scientific and professional advice to the authorities, to the medical profession, and to the public.

The following figures show the changes in the incidence of V.D. in the city of Copenhagen; they

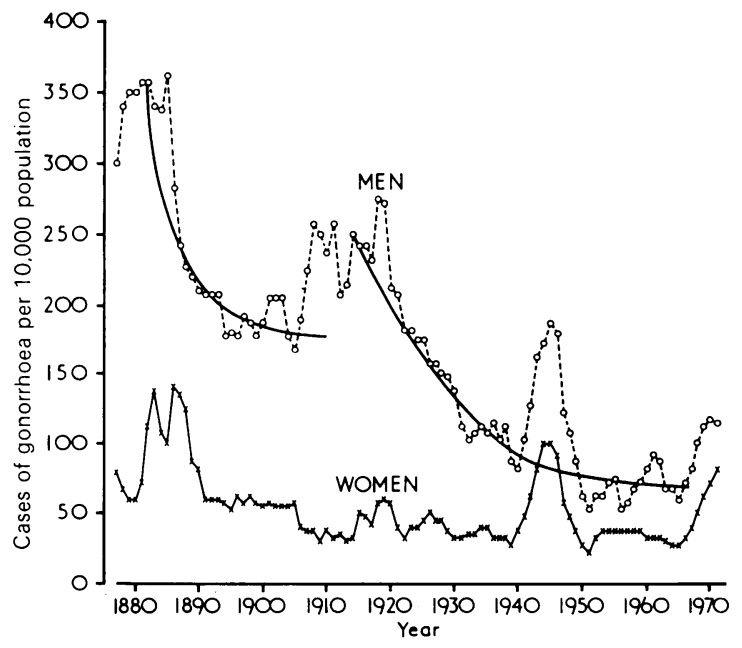

FIG. 1 Gonorrhoea in Copenhagen, 1877-1970, in men and women 
are unusual in that they cover nearly a century of statistics.

Fig. 1 (p. 175) shows that the curve for gonorrhoea seems to express an equilibrium between the attack of the epidemic on society and society's defence. This equilibrium must of course depend on a variety of mechanisms on both sides. The curve is interrupted from time to time by various events mentioned in Table II.

Fig. 2 shows the incidence of syphilis in males. After the first world war the introduction of systemic neosalvarsan * and later of neosalvarsan plus bismuth caused a dramatic decrease in the incidence of syphilis. An obvious decrease is again seen in the 1950s, because of the widespread use of penicillin. The

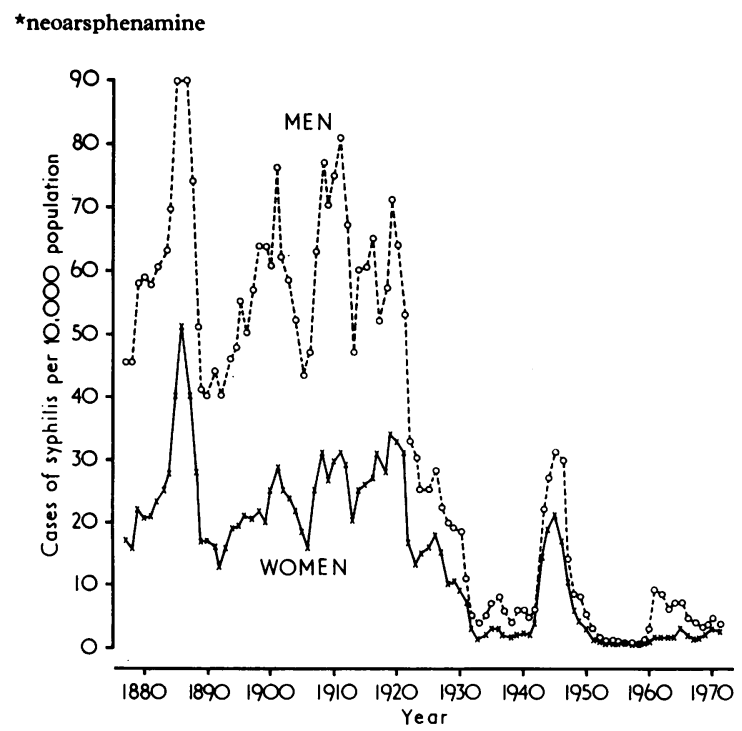

FIG. 2 Syphilis in Copenhagen, 1877-1970, in men and women trend towards total eradication is interrupted after 1960 , possibly because of an epidemic among homosexuals.

Fig. 2 also shows the same trends in syphilis in females, but the increase in the early 1960s is not so obvious.

In the period covered by these graphs Denmark has had very rigorous anti-V.D. legislation. I wonder whether members of the IUVDT from countries with less severe laws or with no anti-V.D. legislation at all, e.g. England, feel that the trends of the incidence of V.D. in their countries are the same as in Denmark.

If this paper should give rise to debate, the subject should be: Are most legal provisions against V.D. patients an anachronism?

\section{References}

Ekstrøm, K. (1972) Thesis. Munksgaard, Copenhagen Gustavsson, N. (1971) Lakartidningen, 68, 4280.

Guthe, T. (1970) 'Worldwide Epidemiological Trends in Syphilis and Gonorrhoea'. Pan-American Health Conference. Washington, D.C.

MARTIN-BOUYER, G. (1972) WHO Symposium on Intercountry Spread of Venereal Diseases, 1971. Copenhagen

PERdRUP, A. (1961) Brit. f. vener. Dis., 37, 115

WHO (1965) International Digest of Health Legislation. Tasmania, 16, 14

-Idem, New Zealand, 16, 367

- Idem, Poland, 16, 729

WHO (1966) Idem, Canada, State of Alberta, 17, 21

-Idem, New South Wales, 17, 415

- Idem, Yugoslavia, 17, 993

WHO (1967) Idem, Columbia, 18, 303

Idem, Czechoslovakia, 18, 343

WHO (1968) Idem, Chile, 19, 170

- Idem, Madagascar, 19, 208

WHO (1969) Idem, Czechoslovakia, 20, 429

WHO (1970) Idem, South Australia, 21, 236

Idem, Western Germany, 21, 286 